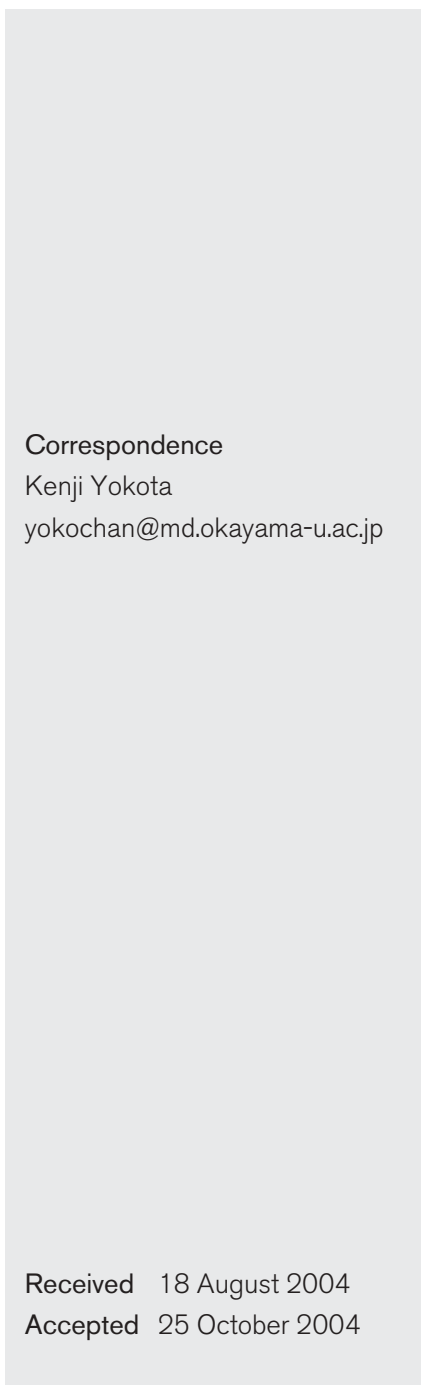

\title{
Helicobacter pylori heat-shock protein 60 induces production of the pro-inflammatory cytokine IL8 in monocytic cells
}

\author{
Song-Nan Lin, ${ }^{1,2}$ Kiyoshi Ayada, ${ }^{1}$ Ying Zhao, ${ }^{1}$ Kenji Yokota, ${ }^{1}$ \\ Ryuta Takenaka, ${ }^{3}$ Hiroyuki Okada, ${ }^{3}$ Rui Kan, ${ }^{1}$ Shyunji Hayashi, ${ }^{4}$ \\ Motowo Mizuno, ${ }^{5}$ Yoshikazu Hirai, ${ }^{4}$ Yoshihito Fujinami ${ }^{6}$ and Keiji Oguma ${ }^{1}$ \\ 1,2,3 Departments of Bacteriology ${ }^{1}$, Dermatology ${ }^{2}$ and Medicine and Medical Science ${ }^{3}$, Okayama \\ University Graduate School of Medicine and Dentistry, 2-5-1 Shikata-cho, Okayama 700-8558, \\ Japan \\ ${ }^{4}$ Division of Bacteriology, Department of Infection and Immunity, Jichi Medical School, 3311-1 \\ Yakushiji, Minami-Kawauchi-cho, Kouchi-Gun, Tochigi 329-0498, Japan \\ ${ }^{5}$ Gastroenterology, Hiroshima City Hospital, 7-33 Moto-cho, Naka-ku, Hiroshima 730-8518, \\ Japan \\ ${ }^{6}$ National Research Institute of Police Science, 6-3-1 Kashiwanoha, Kashiwa 277-0882, Japan
}

\begin{abstract}
Interleukin 8 (IL8) is usually produced in both epithelial and monocytic cells during bacterial infections, causing inflammation. Helicobacter pylori induces production of IL8 from gastric epithelial cells via its cag pathogenicity island (cag PAI) system, LPS and outer-membrane protein. In some bacteria, heat-shock protein 60 (HSP60) also elicits a strong pro-inflammatory response in cells of the innate immune system. Three recombinant $H$. pylori HSP60 ( $r$ HSP60) proteins of different sizes were produced and one of these was used to raise two monoclonal antibodies (2E7 and 7B5). IL8 production was found to be induced in cultured monocytic cells treated with $\mathrm{H}$. pylori cells or rHSP60 proteins, as measured by ELISA, and the amount of IL8 produced was dosedependent. Pre-incubation of $H$. pylori cells or rHSP60 preparations with the antibody 2E7 significantly inhibited IL8 production from monocytic cells. These results indicated that HSP6O is closely associated with IL8 production in monocytic cells.
\end{abstract}

\section{INTRODUCTION}

Chronic infection with Helicobacter pylori is recognized as the cause of chronic active gastritis, peptic ulcer diseases and mucosa-associated lymphoid tissue (MALT) lymphoma and is an important risk factor for the development of gastric carcinoma (Blaser, 1990; Parsonnet et al., 1991, 1994). The chronic phase of $H$. pylori infection associates adaptive lymphocyte immunity with innate immunity. Colonization of $H$. pylori in the mucosa leads to local infiltration of neutrophils, macrophages (Ernst \& Gold, 2000) and T and B cells specific for $H$. pylori antigens (D'Elios et al., 1997; Di Tommaso et al., 1995). Chronic gastritis is initiated and maintained by cytokines that are secreted by gastric epithelial cells and macrophages. Interleukin 8 (IL8) is one of the principal mediators of the inflammatory response.

Initially, secretion of IL8 was reported from gastric epithelial

Abbreviations: cag PAl, cag pathogenicity island; HSP, heat-shock protein; MALT, mucosa-associated lymphoid tissue. cells co-cultured with live H. pylori (Crabtree et al., 1995) and it was later proposed that this reaction depended on the cag pathogenicity island (cag PAI) (Crabtree et al., 1999). Recently, it was also reported that bacterial surface molecules such as LPS and heat-shock protein 60 (HSP60) of H. pylori are closely associated with gastric inflammation. LPS induced secretion of IL8 via toll-like receptor 4 on host epithelial cells (Su et al., 2003). However, the biological activity of $H$. pylori LPS is lower than that of the LPS of other Gram-negative bacteria (Birkholz et al., 1993; Moran et al., 1992).

H. pylori seems to bind to gastric epithelial cells and mucin via HSP60 (Huesca et al., 1996), and adaptive immunity to HSP60 was induced in H. pylori-infected patients (Hayashi et al., 1998; Sharma et al., 1997). We reported previously that development of lymphoid tissue in patients with MALT lymphoma was associated with HSP60 (Kobayashi et al., 1998). Furthermore, we found that the IgG response to HSP60 was closely associated with gastric inflammation and the pathogenesis of MALT lymphoma (Ishii et al., 2001; 
Kawahara et al. 1999). Studies in vitro have indicated that HSP60 induces IL8 from gastric epithelial cells (Yamaguchi et al., 1999) and IL6 from monocytes/macrophages (Gobert et al., 2004). It has also been reported that the HSP60s of Mycobacterium tuberculosis, Campylobacter rectus and Chlamydia pneumoniae induce the production of IL8 by human monocytic cells, human gingival fibroblasts and human endothelial cells, respectively (Bulut et al., 2002; Flohe et al., 2003; Friedland et al., 1993; Hinode et al., 1998). Therefore, we speculated that $H$. pylori HSP60 might be involved in the activation of macrophages.

To investigate the mechanisms of macrophage activation associated with HSP60, we prepared whole HSP60 (rHSPw; $\mathrm{Met}^{1}-\mathrm{Met}^{545}$ ) and two partial domains (rHSP2, Glu ${ }^{101}$ $\mathrm{Ser}^{200}$, and rHSP4-5, $\mathrm{Ile}^{300}-\mathrm{Gly}^{435}$ ) as GST fusion proteins and six peptides of the rHSP4-5 domain. Two monoclonal antibodies (mAbs) were also prepared by immunizing BALB/ c mice with rHSP4-5. It was found that IL8 was secreted from monocytic cells (U937 and NOMO-1) following treatment with rHSPw and rHSP4-5 as well as with $H$. pylori cells. IL8 induction was inhibited by one of the mAbs against HSP60.

\section{METHODS}

Bacterial strains and cell culture. H. pylori ATCC 43504 cells were cultured on brain heart infusion (BHI) agar (Becton Dickinson) supplemented with $7 \%$ horse blood and incubated at $37^{\circ} \mathrm{C}$ under microaerophilic conditions. After incubation for 5 days, bacteria were harvested in RPMI 1640 with $10 \%$ fetal calf serum (FCS) to an $\mathrm{OD}_{600}$ of 1.0 corresponding to approximately $1 \times 10^{8}$ c.f.u. $\mathrm{ml}^{-1}$. Intact and heat-killed $\left(60{ }^{\circ} \mathrm{C}\right.$ for $\left.30 \mathrm{~min}\right)$ bacterial cells were used to stimulate U937 cells.

H. pylori strain SS-1, Helicobacter felis and Helicobacter hepaticus (kindly provided by A. Lee, University of New South Wales, Sydney, Australia) were cultured on BHI agar supplemented with $7 \%$ horse blood and incubated at $37^{\circ} \mathrm{C}$ under microaerophilic conditions for 5 days. Campylobacter jejuni JCM 2013 were also cultured on BHI agar supplemented with $7 \%$ horse blood and incubated at $37^{\circ} \mathrm{C}$ under microaerophilic conditions for 48 h. Escherichia coli NIH-JC2, Salmonella enterica serotype Enteritidis strain IID 604, Salmonella enterica serotype Typhi strain IID 907, Pseudomonas aeruginosa IFO 3455, Proteus mirabilis (clinical isolate) and Citrobacter freundii (clinical isolate) were cultured on BHI agar for $24 \mathrm{~h}$. Bacterial cells were collected from the agar plates and washed in PBS three times. Cells were disrupted with an ultrasonic sonicator (Astrason) and centrifuged at $20000 \mathrm{~g}$ for $20 \mathrm{~min}$. Supernatants were subjected to a protein assay (Bio-Rad). The soluble cell lysates were used as antigens for ELISA and Western blotting.

U937 (human macrophage-like) and NOMO-1 (human monocytic cell-like) cell lines (Japanese Collection of Research Bioresources) were maintained in RPMI 1640 supplemented with $10 \%$ FCS, 50 U penicillin $\mathrm{G}$ sodium $\mathrm{ml}^{-1}$ and $50 \mu \mathrm{g}$ streptomycin sulfate $\mathrm{ml}^{-1}$. Cultures were maintained at $37{ }^{\circ} \mathrm{C}$ in an atmosphere of $5 \% \mathrm{CO}_{2}$ with $99 \%$ humidity.

Cloning, expression and purification of recombinant protein. The amino acid sequence of $H$. pylori HSP60 was analysed using Genetix software and a search was done for T-cell epitopes and homology to human HSP60. Whole HSP60 (rHSPw; $\mathrm{Met}^{1}-\mathrm{Met}^{545}$ ) and two partial domains (rHSP2, Glu ${ }^{101}-\mathrm{Ser}^{200}$, and rHSP4-5, $\mathrm{Ile}^{300}-\mathrm{Gly}^{435}$ ) were designed and expressed as GST fusion proteins (Yamasaki et al., 2004). Soluble fusion proteins expressed by the GST-HSP clones
(rHSPw, rHSP2 and rHSP4-5) were purified by glutathione-Sepharose 4B (Amersham Pharmacia) affinity chromatography according to the manufacturer's instructions. To exclude the effects of trace amounts of LPS in the recombinant protein preparations, the endotoxin activity of rHSP60 preparations was determined using a Limulus amoebocyte lysate assay kit (BioWhittaker) according to the manufacturer's instructions. The preparations of rHSP2, rHSP4-5and rHSPw contained 20, 23, 30 endotoxin units (EU) ( $\mu$ g protein $)^{-1}$, respectively.

Production of mAbs. mAbs against rHSP4-5 were prepared as previously reported with slight modifications (Oguma et al., 1984). Female BALB/c mice ( 8 weeks old) were inoculated subcutaneously twice at 4 -week intervals with $100 \mu \mathrm{g}$ rHSP4-5 mixed with Freund's incomplete adjuvant. Four weeks after the second injection, a booster dose of $8 \mu \mathrm{g}$ rHSP4-5 was injected intravenously. Three days later, the spleen was removed aseptically and dissociated into a single-cell suspension. The lymphocytes $\left(10^{8}\right.$ cells) obtained were fused with P3 X63-Ag8-U1 myeloma cells ( $10^{7}$ cells) using $50 \%$ polyethylene glycol 4000 (Merck). Fused cells were plated into 96-well tissue-culture plates (CellStar) and grown in HAT medium (RPMI 1640 containing $0 \cdot 1 \mathrm{mM}$ hypoxanthine, $0 \cdot 4 \mu \mathrm{M}$ aminopterin, $0 \cdot 016 \mathrm{mM}$ thymidine and $20 \%$ FCS) at $37^{\circ} \mathrm{C}$. When colonies became visible macroscopically, culture supernatants were screened for the production of anti-rHSP4- 5 Abs by ELISA using plates coated with the recombinant proteins. Ab-producing hybridomas were subcloned in 96-well tissue-culture plates by limiting dilution. RPMI 1640 supplemented with $15 \%$ FCS and $5 \%$ Briclone hybridoma cloning medium (Dainippon Pharmaceutical Co.) was used throughout the experiment. Ab production was checked by ELISA and positive clones were expanded in large-scale cultures. The cells $\left(>10^{7}\right)$ were collected and injected intraperitoneally into BALB/c mice that had been pre-treated 7 days earlier with pristane $(0.3 \mathrm{ml})$. Ascitic fluid was collected and the mAbs were purified by DE52 (Whatman) ion-exchange chromatography. The classes and subclasses of $\mathrm{mAbs}$ obtained were determined with a mouse monoclonal typing kit (mouse MonoAB ID/SP kit; The Binding Site).

ELISA and Western blotting. The reactivity of mAbs to the rHSP60 preparations, bacteria and human cells was checked by ELISA and Western blotting. One microgram of recombinant protein or $5 \mu \mathrm{g}$ bacterial antigen in $100 \mu \mathrm{l}$ coating buffer ( $\mathrm{pH} 9 \cdot 6$ ) was coated on to the wells of a 96-well microtitre plate and left overnight at $4{ }^{\circ} \mathrm{C}$. The wells were blocked using PBS containing $10 \%$ skimmed milk for $2 \mathrm{~h}$ at room temperature. Various concentrations of $\mathrm{mAb}$ were reacted for $2 \mathrm{~h}$ at room temperature and washed with PBS containing $0 \cdot 05 \%$ Tween 20 . Peroxidase-labelled rabbit anti-mouse IgG (Dako) was then added and the plates were incubated for $2 \mathrm{~h}$ at room temperature. After washing, the wells were reacted with ABTS tablets (Roche) as a substrate. The $A_{405}$ was measured on a model 680 ELISA plate reader (Bio-Rad).

Bacterial lysates were subjected to SDS-PAGE and transferred to PVDF membranes (Millipore). After reaction with mAbs, the reaction was detected using peroxidase-labelled rabbit anti-mouse IgG (Dako) as the secondary $\mathrm{Ab}$ and by ECL Western blotting detection reagents (Amersham Pharmacia Biotech). The luminol reaction was detected with an LAS-1000 Mini Bio-imaging Analyser System (Fuji Photo Film).

IL8 production stimulated by bacteria and rHSP60 proteins. U937 and NOMO- 1 cells $\left(5 \times 10^{5}\right.$ cells $\left.\mathrm{ml}^{-1}\right)$ were co-incubated with different concentrations of intact (live) or heat-killed $\mathrm{H}$. pylori, or with the rHSP60s, in 96-well plates for $8 \mathrm{~h}$. The experiment was conducted in triplicate for each concentration. Heat-killed $H$. pylori was prepared by heating intact $H$. pylori at $60{ }^{\circ} \mathrm{C}$ for $30 \mathrm{~min}$ before stimulation. IL8 in cell-culture supernatants was collected by centrifugation and assayed by ELISA using a human IL8 ELISA development kit (Techne). The concentration of IL8 was determined using a standard curve obtained with recombinant IL8. The detection limit of the ELISA was $31 \mathrm{pg} \mathrm{ml}^{-1}$. 
Real-time PCR for IL8 mRNA. Total RNA was isolated from U937 cells using RNAzol-B (Tel-Test). After DNase I (Invitrogen) treatment, cDNA was prepared using ReverTra Dash (Takara). Quantitative PCR analysis was performed on a LightCycler using the LightCycler primer set for human IL8 and G6PDH. Real-time PCR was carried out in $24 \mu \mathrm{l}$ consisting of $10 \mu \mathrm{l}$ cDNA sample, $10 \mu \mathrm{l}$ water, $2 \mu \mathrm{l}$ LightCycler primer set and $2 \mu \mathrm{l}$ LightCycler FastStart DNA master SybrGreen I. The reaction mixtures were loaded into capillary tubes and thermal cycling was carried out as follows: activation of hot-start Taq DNA polymerase at $95^{\circ} \mathrm{C}$ for $10 \mathrm{~min}$, followed by 40 cycles of $95^{\circ} \mathrm{C}$ for $10 \mathrm{~s}, 68^{\circ} \mathrm{C}$ for $10 \mathrm{~s}$ and $72^{\circ} \mathrm{C}$ for $16 \mathrm{~s}$. The DNA concentration was calculated using the LightCycler software and the IL8: G6PDH ratio was calculated.

Inhibition of IL8 production by anti-HSP60 polyclonal and monoclonal Abs. Inhibition of the IL8-inducing activity of $H$. pylori by both polyclonal and monoclonal Abs was observed. Intact or heatkilled H. pylori cells suspended in RPMI 1640 without antibiotics $\left(\mathrm{OD}_{600}=0.5\right)$ were incubated with an equal volume of IgG $(100 \mu \mathrm{g}$ $\mathrm{ml}^{-1}$ in $10 \mathrm{mM} \mathrm{PBS}, \mathrm{pH} 7 \cdot 4$ ) of anti-H. pylori polyclonal Ab (Yunoki et al., 2000), anti-HSP60 mAbs (2E7 and 7B5) or control mAb (anti-type C botulinum toxin) for $30 \mathrm{~min}$ at $37^{\circ} \mathrm{C}$. The bacterial suspension $(500 \mu \mathrm{l})$

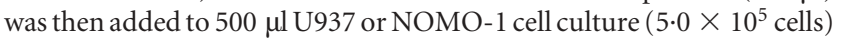
and incubated for $5 \mathrm{~h}$ at $37^{\circ} \mathrm{C}$. The supernatants were used for the IL8 ELISA.

Production of synthetic peptide and ELISA. The domain of rHSP45 was divided into six fragments containing 20 or 23 amino acids (Table 1). Each peptide was synthesized on an Applied Biosystems model 430A synthesizer using $N$-hydroxybenzotriazole esters of tert-butoxycarbonyl amino acids in an $\mathrm{N}$-methylpyrrolidone solvent coupling system as described by the manufacturer. For induction of IL8 from U937 cells, synthetic peptides were added to the cell culture at a concentration of $100 \mu \mathrm{g} \mathrm{ml}^{-1}$. ELISA was performed as described above after coating 96well microtitre plates with the peptides using a Peptide Coating kit (Takara Bio).

Statistical analysis. Results are expressed as means \pm SEM. Data were compared using Scheffe's method and differences were considered significant for values of $P<0 \cdot 05$.

\section{RESULTS}

\section{Intact and heat-killed $H$. pylori and rHSP60s induce IL8 production in monocytic cells}

IL8 production from U937 and NOMO-1 cells was analysed following treatment with various amounts of intact or heat- killed $H$. pylori or with the rHSP60 preparations. Intact or heat-killed $H$. pylori induced secretion of IL8 from U937 cells in a dose-dependent manner (Fig. 1a, b). Intact $H$. pylori stimulation using $>1 \times 10^{6}$ c.f.u. $\mathrm{ml}^{-1}$ induced significant levels of IL8 production. Low concentrations of heat-killed $H$. pylori induced low levels of IL8 production, but high concentrations $\left(>5 \times 10^{7}\right.$ c.f.u. $\left.\mathrm{ml}^{-1}\right)$ of heat-killed $H$. pylori induced IL8 production at levels comparable with intact $H$. pylori stimulation. Production of IL8 from stimulated NOMO-1 cells showed the same trend (Fig. 1c, d).

Cells treated with $1-200 \mu \mathrm{g}$ rHSP4-5 or $\mathrm{rHSPw}^{-1}$ also released IL8. rHSPw and rHSP4-5 preparations induced IL8 production from U937 and NOMO-1 cells in a dosedependent manner (Fig. 2a, b). IL8 secretion was increased significantly by the addition of more than $25 \mu \mathrm{g}$ rHSPw or $50 \mu \mathrm{g} \mathrm{rHSP} 4-5 \mathrm{ml}^{-1}$ in U937 cells. However, IL8 secretion induced by rHSP2 was lower than that of rHSPw and rHSP45. A polymyxin B (PMB)-agarose gel column (Pierce Biotechnology) was used to remove LPS and LPS-associated molecules in the preparation (Gao \& Tsan, 2003). The concentration of LPS in the PMB-agarose column passthrough fractions was less than $10 \mathrm{EU}(2 \mathrm{mg} \text { protein })^{-1}$ (Takenaka et al. 2004). IL8 secretion from U937 and NOMO1 cells was not induced by stimulation with 10 EU E. coli LPS (Sigma), although LPS contamination is not associated with this experiment.

\section{mRNA expression stimulated by rHSP60}

U937 cells $\left(5 \times 10^{5}\right.$ cells $\left.\mathrm{ml}^{-1}\right)$ were stimulated with intact H. pylori $\left(1 \times 10^{6}\right.$ c.f.u. $\left.\mathrm{ml}^{-1}\right)$, heat-killed $H$. pylori $\left(5 \times 10^{6}\right.$ cell $\left.\mathrm{ml}^{-1}\right)$ or $\mathrm{rHSPw}\left(100 \mu \mathrm{g} \mathrm{ml}^{-1}\right)$ and the culture supernatant was collected at various times between 1 and $24 \mathrm{~h}$. IL8 production induced by rHSPw increased from 1 to $9 \mathrm{~h}$, reaching a plateau at $9 \mathrm{~h}$ (Fig. 3a). Real-time PCR was used for IL8 mRNA expression in U937 cells. Expression of IL8 mRNA was maximal at $1 \mathrm{~h}$ and continued for the following 12 h (Fig. 3b).

\section{Characterization of anti-rHSP4-5 mAbs}

Two mAbs (2E7 and 7B5) were obtained. They were classified as IgG2b. The reaction of these mAbs to different rHSP60

Table 1. Synthetic peptides of rHSP4-5

Bold letters indicate amino acids identical to human HSP60. Positions are given relative to the N terminus.

\begin{tabular}{|llcc|}
\hline Peptide & \multicolumn{1}{c}{ Sequence } & Position & $\begin{array}{c}\text { Molecular mass } \\
\text { (Da) }\end{array}$ \\
\hline A & VEFLGKAKIVIDKDNTTIVD & $312-331$ & $2218 \cdot 54$ \\
B & GKGHSHDVKDRVAQIKTQIA & $332-351$ & $2288 \cdot 46$ \\
C & STTSDYDKEKLQERLAKLSG & $352-371$ & $2269 \cdot 47$ \\
D & GVAVIKVGAASEVEMKEKKD & $372-391$ & $2088 \cdot 42$ \\
E & RVDDALSATKAAVEEGIVIG & $392-411$ & $2014 \cdot 25$ \\
F & GGAALIRAAQKVHLNLHDDEKVG & $412-434$ & $2412 \cdot 72$ \\
\hline
\end{tabular}



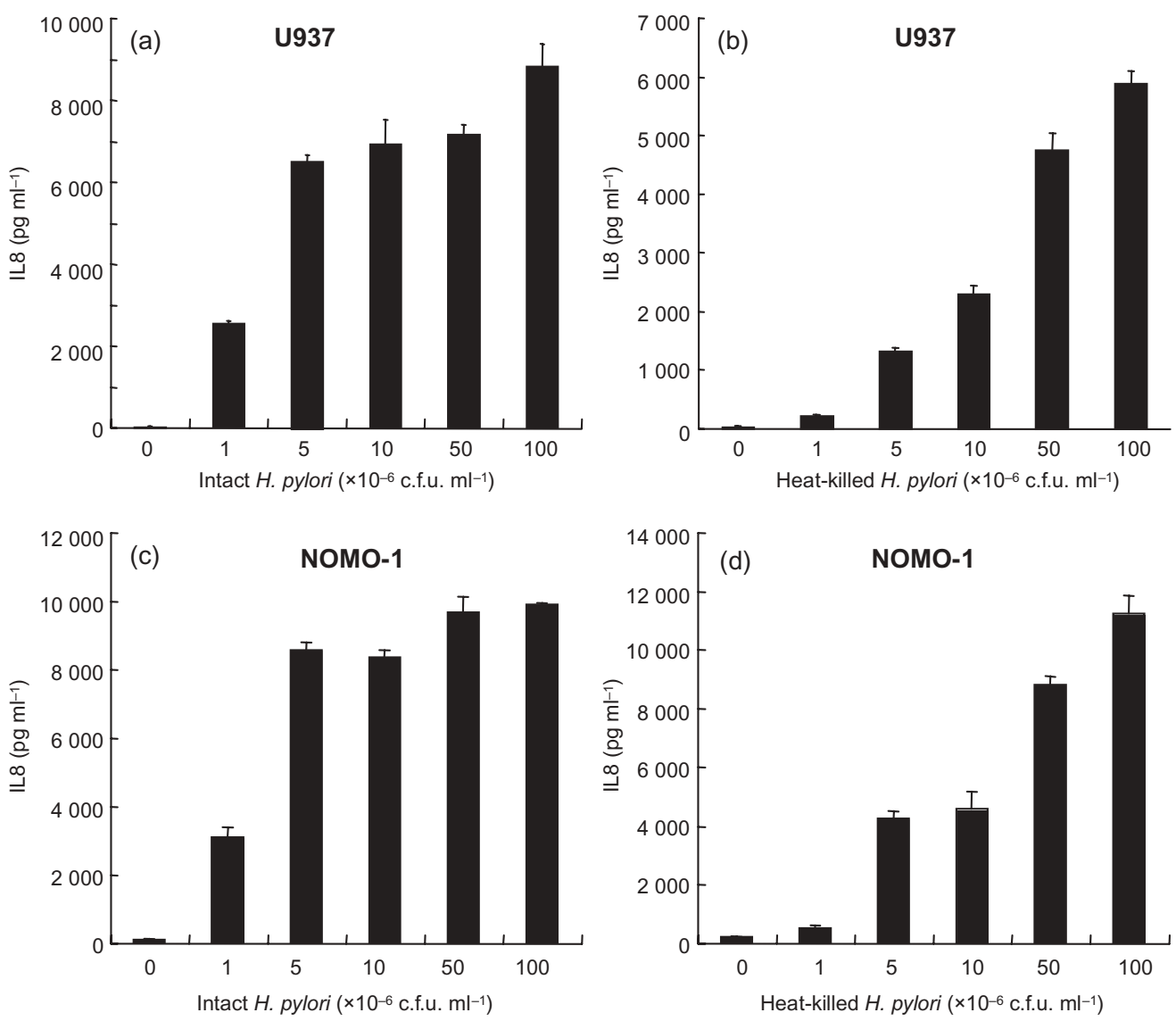

Fig. 1. Induction of IL8 from monocytic cells stimulated with intact or heat-killed H. pylori. U937 (a, b) and NOMO-1 (c, d) cells were stimulated with various amounts $\left(0-10^{8}\right.$ cells $\left.\mathrm{ml}^{-1}\right)$ of intact $(a, c)$ or heat-killed $(b, d)$ cells. After stimulation for $8 \mathrm{~h}$, the culture supernatant was collected and IL8 production was measured by ELISA. Data are expressed as means \pm SEM of three wells.

preparations and bacterial cell lysates was determined by ELISA. The mAbs reacted with rHSPw and rHSP4-5, but not with rHSP2 or human rHSP60 (Stressgen). Data for 2E7 are shown in Fig. 4(a); comparable results were obtained for 7B5. 2E7 and 7B5 did not react with E. coli, S. Enteritidis, S. Typhi, Pseudomonas aeruginosa, Proteus mirabilis and Citrobacter freundii in ELISA and Western blotting (data not shown). mAb 2E7 reacted with $H$. pylori, $H$. felis, Campylobacter jejuni and $H$. hepaticus (Fig. 4b), whereas 7B5 reacted only with $H$. pylori (Fig. 4c). These results were also confirmed by Western blotting (Fig. 4d).

\section{Anti-HSP60 mAb inhibits IL8 production by monocytic cells}

Intact or heat-killed $H$. pylori cells were incubated with antiH. pylori polyclonal IgG, anti-rHSP4-5 mAbs (2E7 and 7B5) or control $\mathrm{mAb}$ (anti-type $\mathrm{C}$ botulinum toxin) and then coincubated with U937 or NOMO-1 cells. The concentration of IL8 in the supernatants was assayed after co-incubation for 8 h. Anti-H. pylori polyclonal Ab and anti-rHSP4-5 mAb (2E7) significantly inhibited IL8 production induced by both intact and heat-killed H. pylori (Fig. 5a). mAb 2E7 inhibited
IL8 production stimulated by both intact and heat-killed $H$. pylori, but 7B5 inhibited IL8 production stimulated by only intact $H$. pylori (Fig. 5b). mAb 2E7 significantly inhibited IL8 production stimulated with $\mathrm{rHSPw}(68 \cdot 2 \%$ inhibition) and rHSP4-5 (57.4\% inhibition). Effective inhibition by 7B5 was not observed following stimulation with rHSP60w and rHSP4-5 (Fig. 5c).

\section{Reactivity of mAbs to synthetic peptides and peptide induction of IL8}

The reaction of synthetic peptides covering the rHSP4-5 domain (peptides A-F; Table 1) to the two mAbs was examined. mAb $7 \mathrm{~B} 5$ reacted strongly with peptides $\mathrm{E}$ and $\mathrm{F}$ but weakly with peptide A, whereas $2 \mathrm{E} 7$ reacted strongly with peptides $\mathrm{A}$ and $\mathrm{D}$ (Table 2). The amino acid sequences of peptides A, B and F are not identical to that of human HSP60 (Table 1). In the induction using these six peptides, only peptide A induced production of IL8 significantly in U937 cells. Peptide B induced a lower level of IL8 production, whereas peptide F did not induce IL8 production (Table 2). 

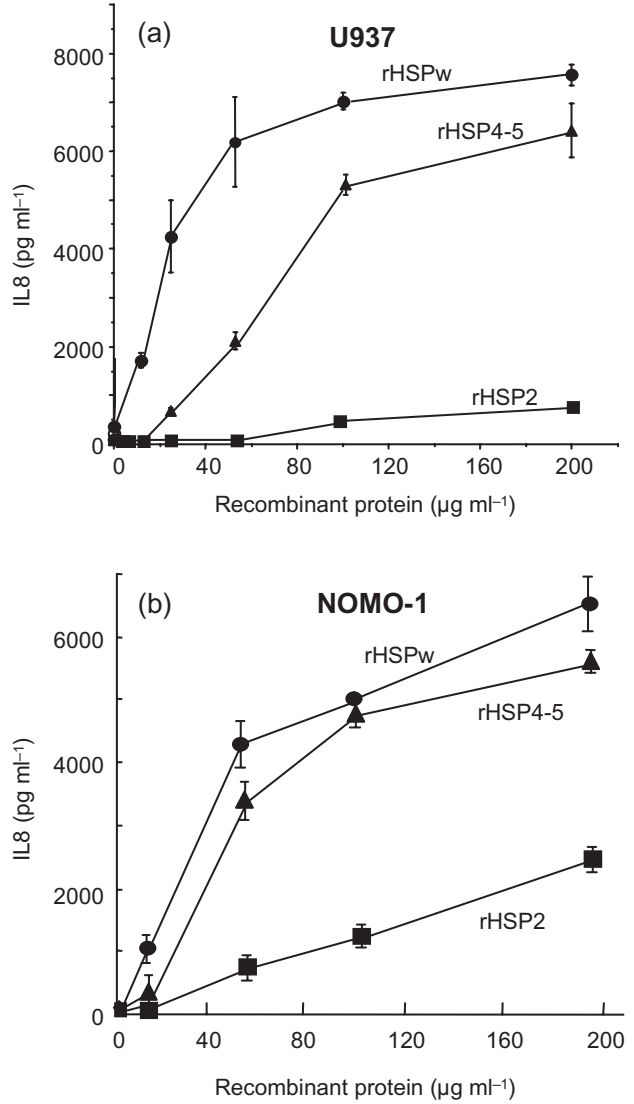

Fig. 2. Induction of IL8 stimulated by rHSP60. U937 (a) and NOMO1 (b) cells $\left(5 \times 10^{5}\right.$ cells $\left.\mathrm{ml}^{-1}\right)$ were cultured in RPMI 1640 and stimulated with different concentrations of rHSP60 preparations. After stimulation for $12 \mathrm{~h}$, the supernatant was collected and the production of IL8 was measured by ELISA. Data are expressed as means \pm SEM of three wells.

\section{DISCUSSION}

We investigated whether HSP60 induced the production of IL8 by monocytic cells. Induction of IL8 was observed following stimulation not only with rHSPw but also with rHSP4-5, indicating that the region $\mathrm{Ile}^{300}-\mathrm{Gly}^{435}$ of HSP60 is associated with induction of IL8 in monocytic cells. This was confirmed using two mAbs (2E7 and 7B5) prepared by immunizing mice with rHSP4-5. Both Abs reacted with rHSPw and rHSP4-5, but not with rHSP2 or human rHSP60, and significantly reduced the IL8-inducing activity. However, their inhibitory effects were different; $2 \mathrm{E} 7$ had a greater effect than 7B5 and inhibited the production of IL8 stimulated by both intact and heat-killed cells, while 7B5 only inhibited the production of IL8 induced by intact $H$. pylori.

$\mathrm{mAb} 2 \mathrm{E} 7$ reacted with peptides A and D of rHSP4-5, whereas 7B5 reacted strongly with peptides $\mathrm{E}$ and $\mathrm{F}$, but weakly with peptide A. It was thus concluded that the epitopes recognized by the two mAbs are different. It was not clear why the mAbs reacted with more than one peptide, but this may explain the differences in their inhibitory effects on IL8 production.
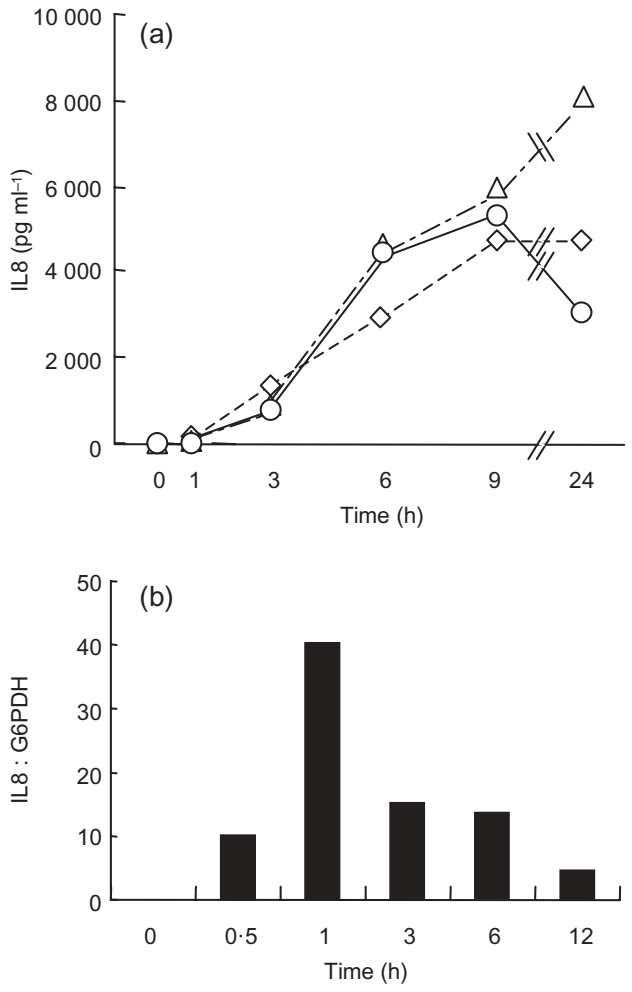

Fig. 3. Induction of IL8 mRNA stimulated by rHSP60. (a) U937 cells were stimulated with $2 \times 10^{6}$ cells of intact $(\diamond)$ or heat-killed $(O) H$. pylori $\mathrm{ml}^{-1}$ or $100 \mu \mathrm{g} \mathrm{rHSPw} \mathrm{ml}^{-1}(\diamond)$. Samples were collected at 0,1 , 3, 6, 9 and $24 \mathrm{~h}$ and IL8 concentration was measured by ELISA. (b) mRNA expression was assayed using real-time PCR. U937 cells were stimulated with $100 \mu \mathrm{g} \mathrm{rHSPw} \mathrm{ml}^{-1}$ and collected at 0, 0.5, 1, 3, 6 and 12 h. The IL8 : G6PDH mRNA expression ratio at each time point was calculated.

Peptide A induced IL8 production in U937 cells compared with peptides B-F, although the level of IL8 was not very high. The amino acid sequences of peptides $\mathrm{A}, \mathrm{B}$ and $\mathrm{F}$ are quite different from that of human HSP60, whereas peptides $\mathrm{C}, \mathrm{D}$ and $\mathrm{E}$ possess similar amino acid sequences to human HSP60. Therefore, it was speculated that the amino acid sequence differences compared with human HSP60, specifically in peptide A, are important for IL8 induction. Monocytic cells may recognize a bacteria-specific sequence or particular conformation of this region and thus induce production of a pro-inflammatory cytokine.

mAb 7B5 reacted strongly with the synthetic peptides in ELISA. However, IL8 secretion was only weakly inhibited, or not inhibited, by $7 \mathrm{~B} 5$ in heat-killed $H$. pylori or rHSP60 stimulations. In contrast, 2E7 had low reactivity to the peptides, but showed high levels of inhibition of IL8 production. Stimulation with the synthetic peptides induced low levels of IL8 production. In fact, recombinant proteins lost this activity if subjected to several freeze-thaw steps (data not shown), indicating that not only the amino acid 

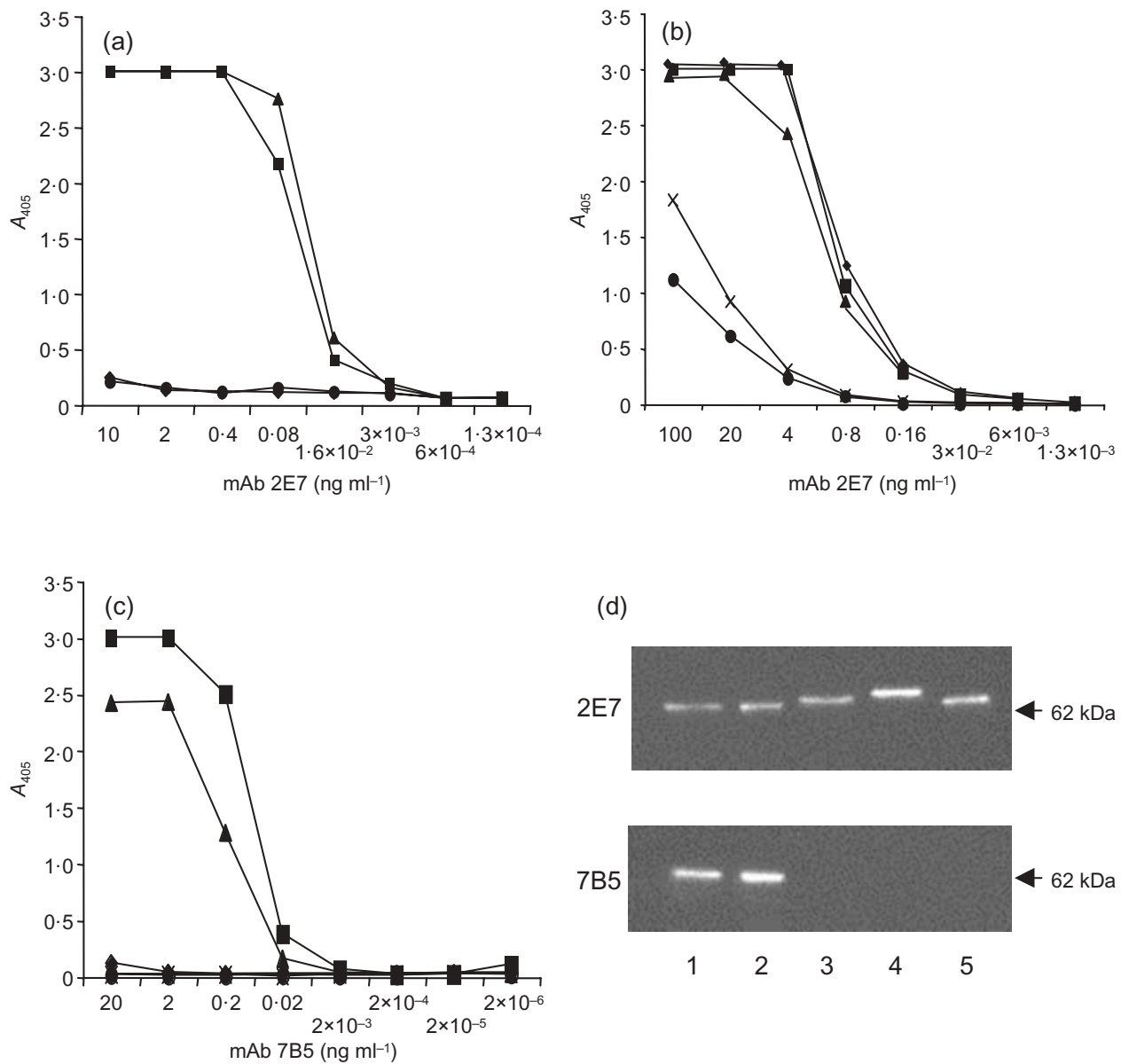

(d)
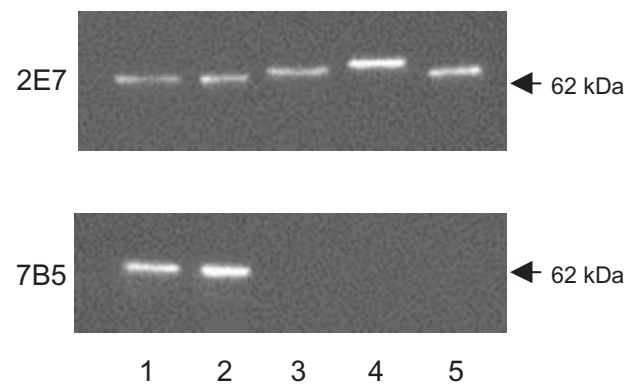

Fig. 4. Reactivity of $m A b s$ to recombinant proteins and bacteria. (a) mAb $2 E 7$ was diluted by 5 -fold serial dilutions (from 10 to $1.3 \times 10^{-4} \mathrm{ng} \mathrm{ml}^{-1}$ ) and reacted with $\mathrm{rHSP} 2(\bullet), \mathrm{rHSP} 4-5(\mathbf{\Lambda}), \mathrm{rHSPw}(\mathbf{-})$ and human rHSP60 (-) by ELISA. (b, c) Different concentrations of 2E7 (b; 5-fold serial dilutions from 100 to $1.3 \times 10^{-3} \mathrm{ng} \mathrm{ml}^{-1}$ ) or $7 \mathrm{~B} 5$ (c; 10-fold serial dilutions from 20 to $2 \times 20^{-6} \mathrm{ng} \mathrm{ml}^{-1}$ ) were reacted with H. pyloriATCC $43504(\mathbf{\Delta})$ and SS-1 ( $\left.\mathbf{}\right)$, H. felis $(\times)$, Campylobacter jejuni $(\mathbf{O})$ and $H$. hepaticus $(\diamond)$ antigens by ELISA. (d) The mAbs were reacted with bacterial antigens for Western blotting and the reaction was detected with a LAS-1000 Mini Bio-imaging Analyser system. Lanes: 1, H. pylori ATCC 43504; 2, H. pylori SS-1; 3, H. felis; 4, Campylobacter jejuni; 5, H. hepaticus.

sequence but also secondary protein structure or the threedimensional structure of the protein on the bacterial surface may be important for IL8 production.

IL8 is a pro-inflammatory cytokine, the actions of which are reported to include neutrophil and T-lymphocyte chemotaxis, neutrophil activation and enhanced expression of neutrophil adhesion molecules (Sherry \& Cerami, 1991). IL8 is released from gastric epithelial cells following stimulation with cag PAI and LPS of H. pylori. In this study, we demonstrated that IL8 was induced in U937 and NOMO-1 cells following stimulation not only with live $H$. pylori cells but also with heat-killed cells. This indicated that the production of IL8 is different from that associated with the Cag A and type IV secretion systems, which are formed only in living $H$. pylori cells. IL8 production was also induced by rHSP60 that had been passed through a column eliminating LPS. Other reports have indicated that not only cag PAI, but also flagella and the LPS, outer-membrane protein and
HSP60 of $H$. pylori are associated with IL8 induction from epithelial cells or monocytes (Bhattacharyya et al., 2002; Cunningham et al., 2000; Lee et al., 2003; Yamaoka et al., 2000; Yamasaki et al., 2004). These non-cag antigens are located on the bacterial surface and have direct contact with host cells. The cag-independent pathway of cytokine induction also may involve inducing mucosal inflammation. Therefore, we concluded that HSP60 is an important molecule for the IL8-inducing system in $\mathrm{H}$. pylori infection.

It is still not clear how the immune system recognizes $H$. pylori early in infection and reacts to the bacteria in the stomach, since MALT does not normally exist in the stomach. Usually, immune responses arise specifically from within organized lymphoid tissue in the intestine (mostly located in the terminal ileum as Peyer's patches) (Wotherspoon, 1998). It seems that $H$. pylori is not able to survive in the human intestine. We have demonstrated here that heat-killed $H$. pylori induced IL8 production by mono- 

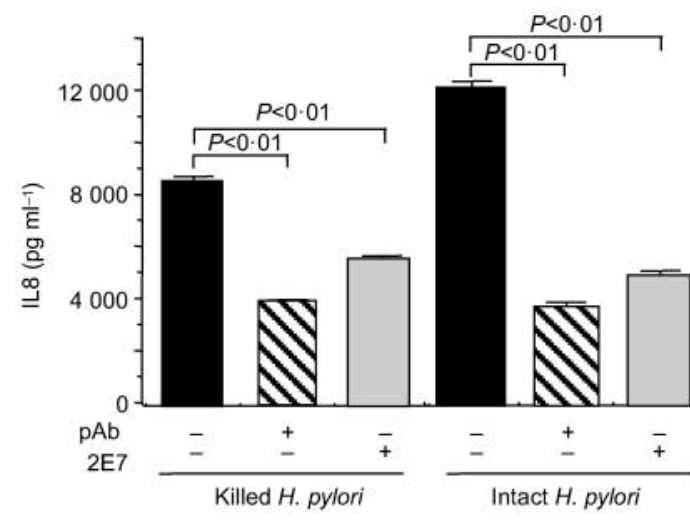

(a)
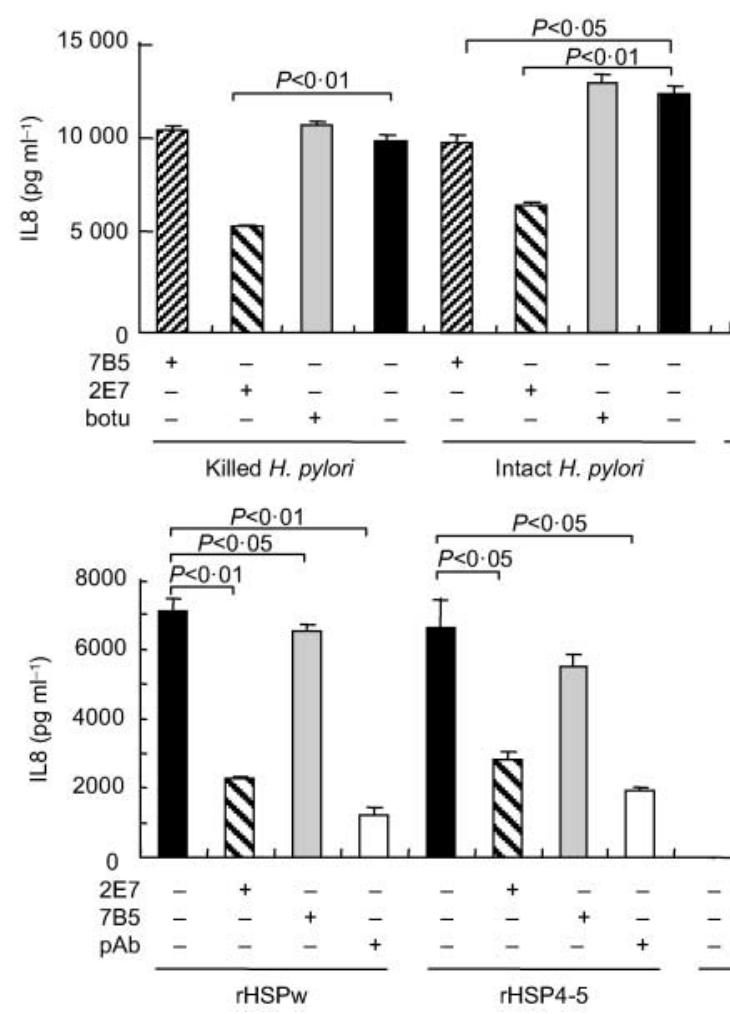

$\stackrel{P<0.05}{\longrightarrow}$

(c)

Table 2. Reactivity of synthetic peptides with mAbs $2 \mathrm{E} 7$ and 7B5, and peptide induction of IL8 in U937 cells

Values for IL8 production are means \pm SEM.

\begin{tabular}{|lccccccc|}
\hline Parameter & \multicolumn{7}{c|}{ Peptide } \\
\cline { 2 - 8 } & A & B & C & D & E & F \\
\hline Reactivity with 7B5 $\left(A_{490}\right)$ & $0 \cdot 22$ & $0 \cdot 08$ & $0 \cdot 10$ & $0 \cdot 28$ & $0 \cdot 95$ & $0 \cdot 46$ \\
Reactivity with 2E7 $\left(A_{490}\right)$ & $0 \cdot 19$ & $0 \cdot 09$ & $0 \cdot 13$ & $0 \cdot 22$ & $0 \cdot 17$ & $0 \cdot 18$ \\
IL8 production $\left(\mathrm{pg} \mathrm{ml}^{-1}\right)$ & $166 \pm 14$ & $130 \pm 19$ & $121 \pm 16$ & $108 \pm 10$ & $104 \pm 11$ & $97 \pm 8$ \\
\hline
\end{tabular}

cytic cells through HSP60. This supports the hypothesis that a bacterial surface component such as HSP60 on H. pylori that has flowed from the stomach into the intestine may activate immune responses through lymphoid tissue such as
Peyer's patches. Some reports have indicated that cell-surface receptors are associated with the recognition of human HSP (Curry et al., 2003; MacDonald et al., 2002; Wang et al., 2002). The receptors on monocytic cells for H. pylori HSP60 
have still to be identified. We are now trying to identify the cell receptor for HSP60 and are also studying IL8 induction in gastric epithelial cells using $H$. pylori and rHSP60 preparations.

The Abs to specific sites recognizing HSP60 sequences of $H$. pylori that were different from human HSP60 inhibited IL8 production. Thus, we believe that specific domains of $H$. pylori HSP60 could be used as effective vaccines for antiinflammatory therapy in the future.

\section{REFERENCES}

Bhattacharyya, A., Pathak, S., Datta, S., Chattopadhyay, S., Basu, J. \& Kundu, M. (2002). Mitogen-activated protein kinases and nuclear factor- $\kappa \mathrm{B}$ regulate Helicobacter pylori-mediated interleukin- 8 release from macrophages. Biochem J 368, 121-129.

Birkholz, S., Knipp, U., Nietzki, C., Adamek, R. J. \& Opferkuch, W. (1993). Immunological activity of lipopolysaccharide of Helicobacter pylori on human peripheral mononuclear blood cells in comparison to lipopolysaccharides of other intestinal bacteria. FEMS Immunol Med Microbiol 6, 317-324.

Blaser, M. J. (1990). Helicobacter pylori and the pathogenesis of gastroduodenal inflammation. J Infect Dis 161, 626-633.

Bulut, Y., Faure, E., Thomas, L., Karahashi, H., Michelsen, K. S., Equils O., Morrison, S. G., Morrison, R. P. \& Arditi, M. (2002). Chlamydial heat shock protein 60 activates macrophages and endothelial cells through Toll-like receptor 4 and MD2 in a MyD88-dependent pathway. J Immunol 168, 1435-1440.

Crabtree, J. E., Covacci, A., Farmery, S. M., Xiang, Z., Tompkins, D. S., Perry, S., Lindley, I. J. \& Rappuoli, R. (1995). Helicobacter pylori induced interleukin-8 expression in gastric epithelial cells is associated with CagA positive phenotype. J Clin Pathol 48, 41-45.

Crabtree, J. E., Kersulyte, D., Li, S. D., Lindley, I. J. \& Berg, D. E. (1999). Modulation of Helicobacter pylori induced interleukin-8 synthesis in gastric epithelial cells mediated by cag PAI encoded VirD4 homologue. J Clin Pathol 52, 653-657.

Cunningham, M. D., Shapiro, R. A., Seachord, C., Ratcliffe, K., Cassiano, L. \& Darveau, R. P. (2000). CD14 employs hydrophilic regions to "capture" lipopolysaccharides. J Immunol 164, 3255-3263.

Curry, J. L., Qin, J. Z., Bonish, B., Carrick, R., Bacon, P., Panella, J., Robinson, J. \& Nickoloff, B. J. (2003). Innate immune-related receptors in normal and psoriatic skin. Arch Pathol Lab Med 127, 178-186.

D'Elios, M. M., Manghetti, M., Almerigogna, F. \& 7 other authors (1997). Different cytokine profile and antigen-specificity repertoire in Helicobacter pylori-specific $\mathrm{T}$ cell clones from the antrum of chronic gastritis patients with or without peptic ulcer. Eur J Immunol 27, 17511755.

Di Tommaso, A., Xiang, Z., Bugnoli, M., Pileri, P., Figura, N., Bayeli, P. F., Rappuoli, R., Abrignani, S. \& De Magistris, M. T. (1995). Helicobacter pylori-specific $\mathrm{CD}^{+}{ }^{+} \mathrm{T}$-cell clones from peripheral blood and gastric biopsies. Infect Immun 63, 1102-1106.

Ernst, P. B. \& Gold, B. D. (2000). The disease spectrum of Helicobacter pylori: the immunopathogenesis of gastroduodenal ulcer and gastric cancer. Annu Rev Microbiol 54, 615-640.

Flohe, S. B., Bruggemann, J., Lendemans, S., Nikulina, M., Meierhoff, G., Flohe, S. \& Kolb, H. (2003). Human heat shock protein 60 induces maturation of dendritic cells versus a Th1-promoting phenotype. J Immunol 170, 2340-2348.

Friedland, J. S., Shattock, R., Remick, D. G. \& Griffin, G. E. (1993).
Mycobacterial 65-kD heat shock protein induces release of proinflammatory cytokines from human monocytic cells. Clin Exp Immunol 91, $58-62$.

Gao, B. \& Tsan, M. F. (2003). Recombinant human heat shock protein 60 does not induce the release of tumor necrosis factor alpha from murine macrophages. J Biol Chem 278, 22523-22529.

Gobert, A. P., Bambou, J. C., Werts, C., Balloy, V., Chignard, M., Moran, A. P. \& Ferrero, R. L. (2004). Helicobacter pylori heat shock protein 60 mediates interleukin- 6 production by macrophages via a toll-like receptor (TLR)-2-, TLR-4-, and myeloid differentiation factor 88independent mechanism. J Biol Chem 279, 245-250.

Hayashi, S., Sugiyama, T., Yokota, K., Isogai, H., Isogai, E., Oguma, K., Asaka, M., Fujii, N. \& Hirai, Y. (1998). Analysis of immunoglobulin A antibodies to Helicobacter pylori in serum and gastric juice in relation to mucosal inflammation. Clin Diagn Lab Immunol 5, 617-621.

Hinode, D., Yoshioka, M., Tanabe, S., Miki, O., Masuda, K. \& Nakamura, R. (1998). The GroEL-like protein from Campylobacter rectus: immunological characterization and interleukin- 6 and -8 induction in human gingival fibroblast. FEMS Microbiol Lett 167, 1-6.

Huesca, M., Borgia, S., Hoffman, P. \& Lingwood, C. A. (1996). Acidic $\mathrm{pH}$ changes receptor binding specificity of Helicobacter pylori: a binary adhesion model in which surface heat shock (stress) proteins mediate sulfatide recognition in gastric colonization. Infect Immun 64, 26432648.

Ishii, E., Yokota, K., Sugiyama, T. \& 7 other authors (2001). Immunoglobulin G1 antibody response to Helicobacter pylori heat shock protein 60 is closely associated with low-grade gastric mucosa-associated lymphoid tissue lymphoma. Clin Diagn Lab Immunol 8, 1056-1059.

Kawahara, Y., Yokota, K., Mizuno, M. \& 7 other authors (1999). Antibodies to human gastric epithelial cells and heat shock protein 60 in Helicobacter pylori positive mucosa associated lymphoid tissue lymphoma. Gut 45, 20-23.

Kobayashi, K., Yokota, K., Yoshino, T., Kawahara, Y., Dey, A., Hirai, Y., Oguma, K. \& Akagi, T. (1998). Detection of Helicobacter pylori associated antigen and heat shock protein 60 on follicular dendritic cells in the germinal centres of low grade B cell lymphoma of gastric mucosa associated lymphoid tissue (MALT). J Clin Pathol 51, 396-398.

Lee, S. K., Stack, A., Katzowitsch, E., Aizawa, S. I., Suerbaum, S. \& Josenhans, C. (2003). Helicobacter pylori flagellins have very low intrinsic activity to stimulate human gastric epithelial cells via TLR5. Microbes Infect 5, 1345-1356.

MacDonald, A. J., Duffy, M., Brady, M. T., McKiernan, S., Hall, W., Hegarty, J., Curry, M. \& Mills, K. H. (2002). CD4 T helper type 1 and regulatory $\mathrm{T}$ cells induced against the same epitopes on the core protein in hepatitis C virus-infected persons. J Infect Dis 185, 720-727.

Moran, A. P., Helander, I. M. \& Kosunen, T. U. (1992). Compositional analysis of Helicobacter pylori rough-form lipopolysaccharides. J Bacteriol 174, 1370-1377.

Oguma, K., Murayama, S., Syuto, B., lida, H. \& Kubo, S. (1984). Analysis of antigenicity of Clostridium botulinum type $\mathrm{C} 1$ and D toxins by polyclonal and monoclonal antibodies. Infect Immun 43, 584-588.

Parsonnet, J., Friedman, G. D., Vandersteen, D. P., Chang, Y., Vogelman, J. H., Orentreich, N. \& Sibley, R. K. (1991). Helicobacter pylori infection and the risk of gastric carcinoma. N Engl J Med 325, 11271131.

Parsonnet, J., Hansen, S., Rodriguez, L., Gelb, A. B., Warnke, R. A., Jellum, E., Orentreich, N., Vogelman, J. H. \& Friedman, G. D. (1994). Helicobacter pylori infection and gastric lymphoma. N Engl J Med 330, 1267-1271.

Sharma, S. A., Miller, G. G., Peek, R. A., Jr, Perez-Perez, G. \& Blaser, M. 
J. (1997). T-cell, antibody, and cytokine responses to homologs of the 60-kilodalton heat shock protein in Helicobacter pylori infection. Clin Diagn Lab Immunol 4, 440-446.

Sherry, B. \& Cerami, A. (1991). Small cytokine superfamily. Curr Opin Immunol 3, 56-60.

Su, B., Ceponis, P. J., Lebel, S., Huynh, H. \& Sherman, P. M. (2003). Helicobacter pylori activates Toll-like receptor 4 expression in gastrointestinal epithelial cells. Infect Immun 71, 3496-3502.

Takenaka, R., Yokota, K., Ayada, K. \& 8 other authors (2004). Helicobacter pylori-heat shock protein 60 induces inflammatory responses through the Toll-like receptor-triggered pathway in cultured human gastric epithelial cells. Microbiology 150, 3913-3922.

Wang, Y., Kelly, C. G., Singh, M., McGowan, E. G., Carrara, A. S., Bergmeier, L. A. \& Lehner, T. (2002). Stimulation of Th1-polarizing cytokines, $\mathrm{C}-\mathrm{C}$ chemokines, maturation of dendritic cells, and adjuvant function by the peptide binding fragment of heat shock protein 70 . J Immunol 169, 2422-2429.
Wotherspoon, A. C. (1998). Gastric lymphoma of mucosa-associated lymphoid tissue and Helicobacter pylori. Annu Rev Med 49, 289-299.

Yamaguchi, H., Osaki, T., Kurihara, N., Kitajima, M., Kai, M., Takahashi, M., Taguchi, H. \& Kamiya, S. (1999). Induction of secretion of interleukin-8 from human gastric epithelial cells by heat-shock protein 60 homologue of Helicobacter pylori. J Med Microbiol 48, 927-933.

Yamaoka, Y., Kwon, D. H. \& Graham, D. Y. (2000). A $M_{\mathrm{r}} 34,000$ proinflammatory outer membrane protein (oipA) of Helicobacter pylori. Proc Natl Acad Sci U S A 97, 7533-7538.

Yamasaki, R., Yokota, K., Okada, H. \& 7 other authors (2004). Immune response in Helicobacter pylori-induced low-grade gastric-mucosaassociated lymphoid tissue (MALT) lymphoma. J Med Microbiol 53, 21-29.

Yunoki, N., Yokota, K., Mizuno, M. \& 7 other authors (2000). Antibody to heat shock protein can be used for early serological monitoring of Helicobacter pylori eradication treatment. Clin Diagn Lab Immunol 7, $574-577$. 